\title{
Application of Model View Controller Architecture in Hospital Inventory Logistic Management
}

\author{
Iwan Santosa ${ }^{1}$, Firman Kurniawan ${ }^{2}$, Eza Rahmanita ${ }^{3}$, Aeri Rachmad ${ }^{4}$ \\ Department of Informatics Engineering \\ University of Trunojoyo Madura \\ Bangkalan, Indonesia \\ ${ }^{1}$ iwan@trunojoyo.ac.id
}

\begin{abstract}
An inventory control system is a system to determine stock inventory at a certain time. This happens because there are several problems, namely the difficulty in finding out information on requests, receipts, usage, and stock of consumables. This happens because the data is not stored in a good file and the management of inventory data is still done manually using an inventory card. The process of checking the supply of goods in the warehouse is still single user so that when doing stock inventory the inventory cannot be used multiusers so that the service and Logistics Head cannot directly access the stock opname report. Problems like this require a computerized system and use a multiuser system. The system development methodology used in this research is the waterfall method which includes needs analysis, design, implementation, testing and maintenance. Inventory Logistic Management System is the right solution, which is by combining web-based applications with the Model View Controller (MVC). The purpose of this study using MVC is to see the level of effectiveness of MVC use and measure the level of user satisfaction. The results of this research are the ease of software development and maintenance and user satisfaction with an average survey value of 7.96 and a trial of a system that works well. This application can significantly simplify the work flow of goods distribution and report the distribution of goods in the Hospital. From this research, the authors contributed to the use of MVC which facilitated the implementation, development and maintenance of software and supported by the results of user satisfaction.
\end{abstract}

Keywords—MVC Model; inventory logistic; user satisfaction

\section{INTRODUCTION}

RSUD dr. H. Slamet Martodirdjo has a logistics warehouse, which serves as a storage, data collection and distribution of various items needed for hospital operations. In the logistics warehouse there are various items, such as office stationery (ATK), cleaning equipment, printing, household appliances, and many others. So that the hospital needs a good recording system so that the items contained in the logistics warehouse can be recorded properly. The complexity of work in the logistics warehouse causes the hospital to provide a small amount of resources for logistics warehouse operations.

To provide hospital resources requires a small budget. But the limited source of funds for the logistics warehouse caused the hos pital to suppress operations in the logistics warehouse. In addition, the demand system and manual recording of items causes more workload for Warehouse Administrators. The complexity of the workflow in the logistics warehouse has raised problems that are also very complex. As a solution to the complex problems that occur in the logistics warehouse, researchers have designed a logistics management system so that each user in the workflow in the logistics warehouse can work efficiently, quickly and accurately.

The system built has implemented the MVC (Model View Controller) concept. The MVC concept was chosen because it was able to provide convenience to researchers to design a good system with limited resources. In addition, users can use the system easily because it has been designed as well as possible. With the implementation of this system will be able to reduce the workload for Warehouse Admin and all other users who have a role in the workflow in the logistics warehouse.

MVC is a typical paper architecture model that develops the advantages of the MVC pattern, discusses the development process based on MVC software patterns, and designs a Web application-library management system [1]. In some studies the use of MVC has resulted in several conveniences in building software systems. In a study produce the complexity of the code in software can be significantly reduced and increase the flexibility and modularity of software systems [2]. Implementation of the Model-View Controller Framework In the Lampung University Academic Information System produces consistency between views with a flexible interface approach and can represent information in various forms [3].

Application of Model View Controller (MVC) Architecture in the Design of Extensions A Content Management System results in increased modularity and reusability of the system. Source code becomes neater and the separation between business logic and more explicit user interface [4]. E-Commerce Website Using View Controller Models With Codeigniter Framework. With MVC Architecture implemented with this Codeigniter Framework, applications become easier to develop by the next programmer [5]. Comparison of MVC Framework (Codeigniter and Cakephp) on web-based applications can be concluded that to create a web trusteeship in the Informatics Department of the framework of a good National Institute of Technology using codeigniter and for further development using the cakephp 
framework because the architecture in cakephp reflects pure MVC [6].

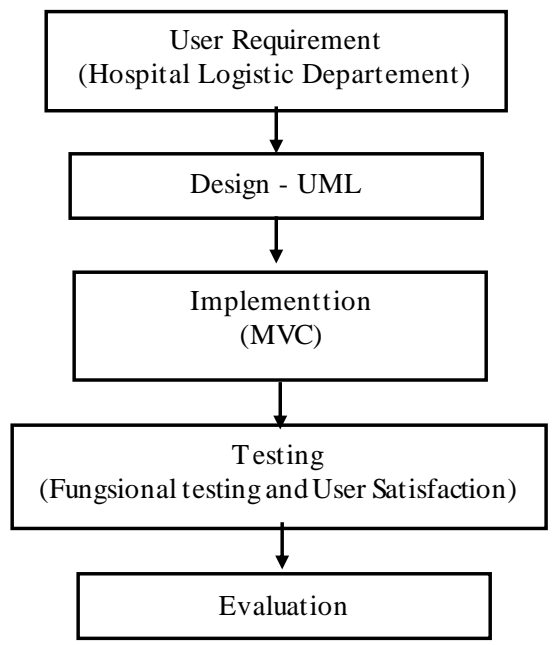

Fig. 1. Riset Structure

The method used in designing and implementing software is to use the Waterfall model. In this model the process runs sequentially from one phase to the next [7]. Each schedule of the phase is completed within a certain time. Documentation and testing occur at the end of each phase to help maintain the quality of the project. Each step will be finalized before heading to the next phase. Figure 1 shows the structure of the research that has been carried out.

\section{METHODS}

The method used in this study is the waterfall model using the waterfall development process method. This model is a classic model that is simple, structured and linear because the process just flows from beginning to end. This model provides a systematic and sequential approach [8].

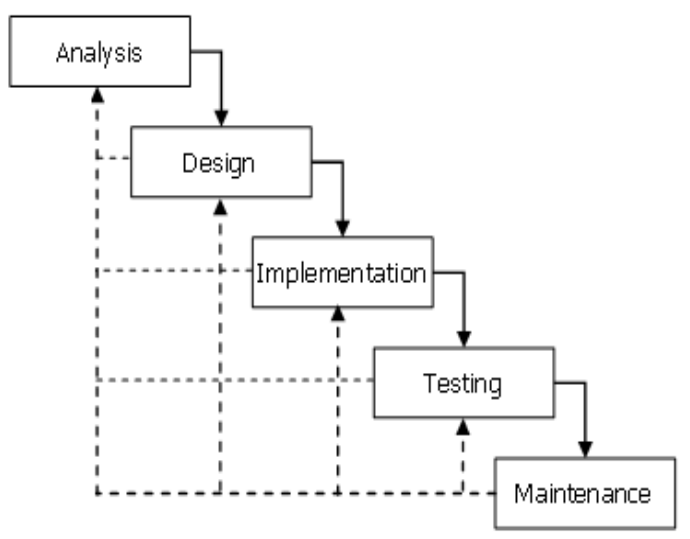

Fig. 2. Waterfall Model[9]

In the Analysis phase, the software developer makes a description of the system to be developed [10]. In this process, the collection of all information needs is taken from the client, in this case the data was taken from the RSUD hospital. dr. H. Slamet Martodirdjo. Collection of system requirements what to do or how to do. There are two types of needs that will be identified. The first type is functional needs that capture what the system. The second type is non-functional needs that capture the constraints on the system itself, as well as the constraints faced by the system in the development stage. Each functional and non-functional need is analyzed in detail. Object-oriented analysis techniques have been chosen to further identify the system requirements that are detailed using UML (Unified Modeling Language). System requirements are translated into graphical notation using UML. Each use case is associated with an actor, so that each use case states the purpose of the actor in using the system. It also shows the interaction between the actor and the system.

System design stage, technical design starts to be defined which contains detailed designs for each use case. All use cases presented in the analysis phase will be detailed and presented in three diagrams namely sequence diagrams, class diagrams, and activity diagrams. Sequence diagrams are used to describe interactions that are arranged in a time sequence. Class diagrams are used to model the classes to be used, which will later also be transformed in the form of tables of a database as a place to store data, while activity diagrams to model the processes that take place in this adaptive online quiz system. Database design is described as a form of data modeling and user interface design will also be described in this stage as a form of system interface with users [9].

Implementation using the MVC architecture is that it will create data models to represent information from the database, view to display data, and a controller that will combine the two together and handle other tasks. The MVC concept looks like Fig. 2 below.

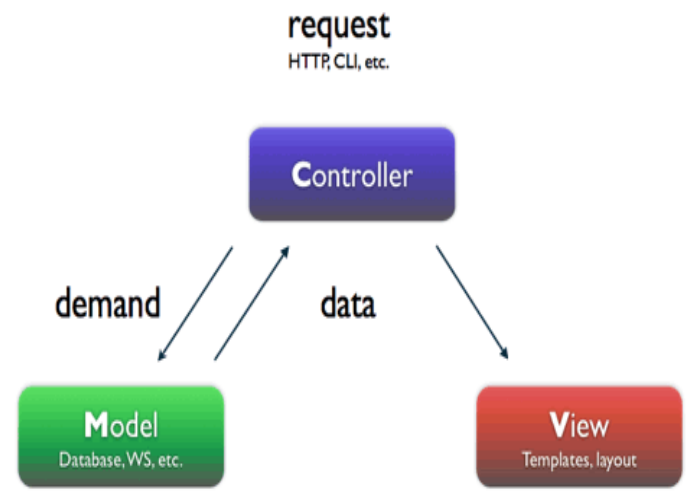

Fig. 3. MVC Model[11]

Logistic Information Management testing is carried out with the aim to find out the compatibility between system functions or services that are implemented with the results of the needs analysis that has been determined at the functional and non-functional needs analysis stage. Testing is also conducted to find out whether the system can be accessed using several internet browser software. Besides that, by doing the testing, it can be seen that there are errors in the coding process and in producing the output of the program so that these errors can be corrected. 


\section{RESULTS AND DISCUSSION}

At the Analysis Stage the collection of information on the procurement of goods in the logistics of the hospital, each room submits a request for goods needed in their room to the head of the department or head of their respective fields. Then the task of the head of the department and the head of the field is to approve the request for goods submitted every room in the hos pital. After being approved by the section head or field head, the next process is signed by the planning department. The task of the planning section is to send a request file for goods that have been signed by the planning department and the hos pital director to the supplier.

The supplier receives the goods request file from the hospital, collects the goods on demand and sends the goods to the logistics department which is directed directly to the PPHP (the Work Recipient Committee). Arriving at PPHP, the Committee checks the items that have arrived. See the condition of the goods demanded and calculate the number of items according to the request. PP (Administrative Assistance) Goods receive and store items according to their place. And PP Goods provide file data of goods entered into the logistical admin to be recorded on the inventory card.

In the process of distributing goods in hospital logistics, there are stages. The first stage of the head of each room must fill out a card requesting the goods containing the details of the items to be submitted to PPTK (Activity Technician). After completing the item request card, PPTK signs a request card that contains the name of the item submitted to the logistics. PP (Administrative Assistants) The goods fill in the list of items requested in each room. After filling in, the sheet is signed and the item is prepared. Then PP Goods provides a list of goods requests to the admin logistics to record the items out on the inventory card.

At the design stage, information about the data flow that comes from the user, from the part of the hospital, is made usecase diagrams, activity diagrams, sequence diagrams and CDM and PDM. This is adjusted to the flow of information obtained from the analysis phase.

The system that has been designed is then implemented into the program code using the PHP programming language with Codeigniter as its framework. This section will present a sourcecode to demonstrate the application of the MVC concept to the main features of the logistics management system.

The model is used for data manipulation of goods. It shows in figure 4. This part of source code serves to interact directly with the database used in the system. There are several main functions that function in data manipulation.

The view in figure 5 on MVC only contains codes that function to form a user interface for the system. This source code is a piece of HTML code to display menus from the system. Files from this source code are located in the views folder. In order for the system to use this source code, the researcher needs to make a control that can control the entire source code, both model and view.

On the part of source code from this controller that show in figure 6 , there is a function construct that functions to load the model for system requirements. There is also a render page function that functions to load the views needed by the system.

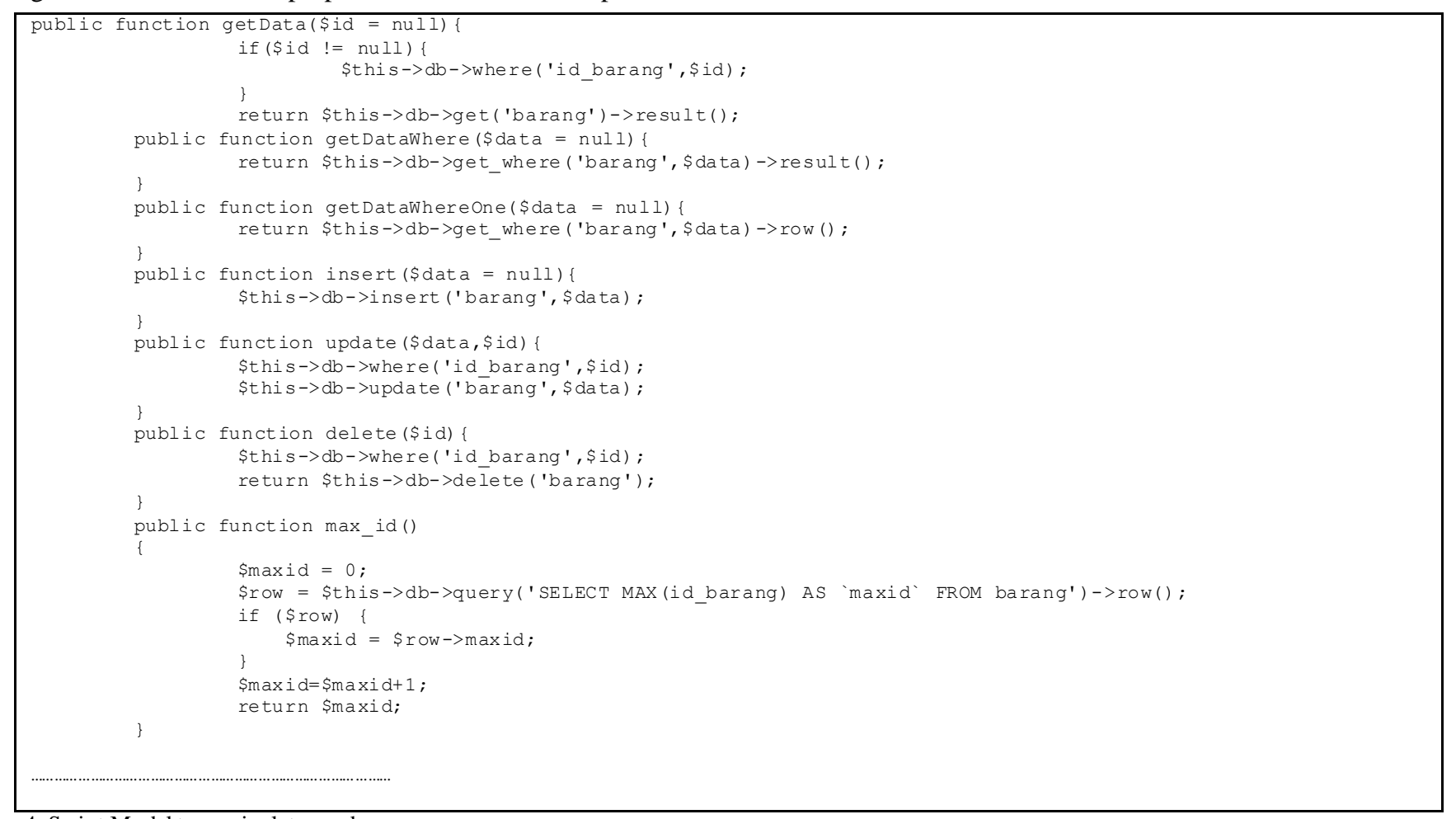

Fig. 4. Script Model to manipulate goods 
System testing is carried out to determine how well the system is operating and in accordance with its function. System testing is carried out by users who only have access rights to the system. Users who have system access rights include Admin Room, Head of Office , Planning Departement, Head of Room and Warehouse Admin.

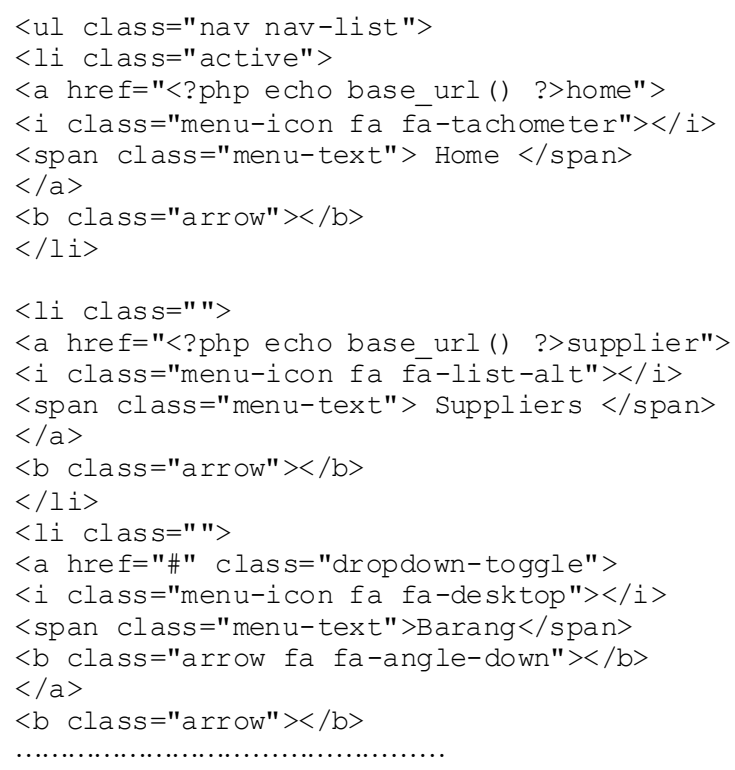

Fig. 5. Script View to display the menu

With the system testing, it can be seen the suitability of features with user needs, bugs in the system will be seen so that they can be fixed immediately. In testing this system is directly operated by the user concerned and also by distributing questionnaires to users who have access rights to the system.

The system testing scenario is carried out by distributing questionnaires to users of RSUD. dr. H. Slamet Martodirdjo who has an account to access inventory logistics applications. Questionnaires are given to users who have access rights in the system. The user is the Head of Room, Room Admin, Head of Division, Planning Departement, Section Head, and Warehouse Admin.

The assessment for the questionnaire that has been filled in by the user will be processed further by doing the following process:

1. Calculate the average for each variable.

2. Grouping the results of the calculation of each variable into three categories, namely:

a. Good, if the average value is $>7.5$

b. Enough, if $7.5 \Rightarrow$ average $=>5.0$

c. Less, if the average value is $<5.0$

From the results of the questionnaire distributed to users, the value data contained in Table 1 .

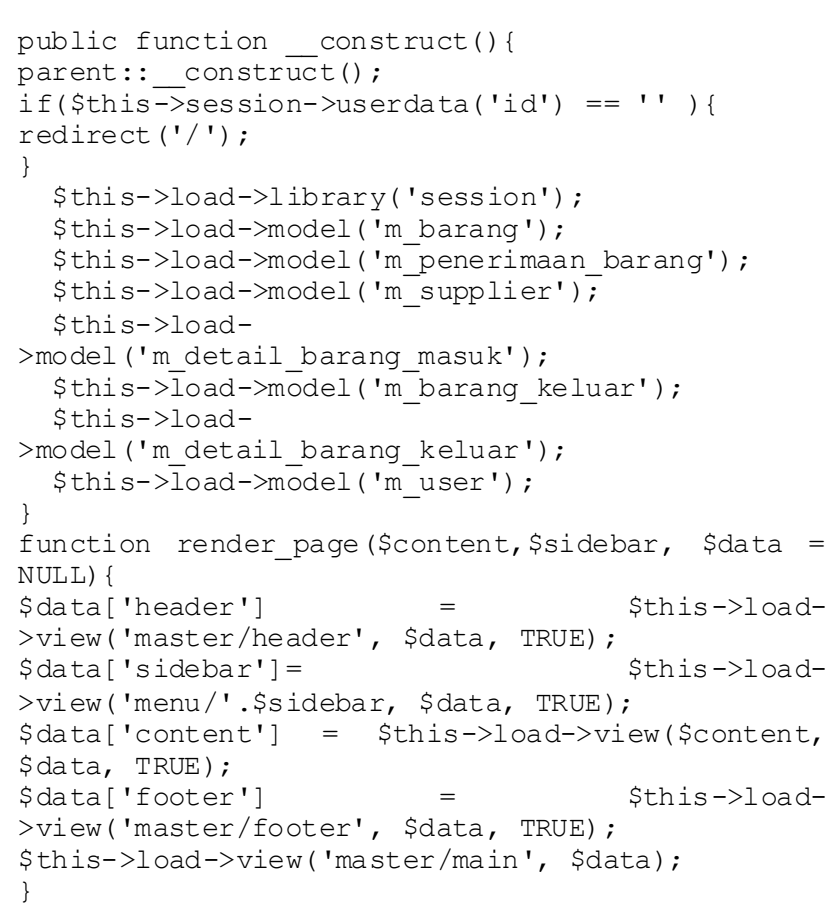

\section{Figure 6. Script Controller for loading}

Based on the results of the questionnaire distributed to users can be obtained the following calculation values:

1. Ease of access to Logistic Inventory Management System $=8$

2. Interface Design Logistic Inventory Management System $=8.1$

3. Ease of obtaining information on stock items $=7.4$

4. Clarity of information and data available $=7.6$

5. Completeness of existing information and data $=7.8$

6. Ease of operation of the Logistic Inventory Management System $=7.9$

7. Completeness of Logistic Inventory Management System features $=7.7$

8. Ease in making reports $=8$

9. Security Level of Logistic Inventory Management System $=7.8$

10. Assessment of the Logistics Inventory Management System as a whole $=8.5$.

From the results of the questionnaire, the calculation of the average value of each variable in table 1 can be obtained from the average assessment results from users working in the logistics department of the RSUD. dr. H. Slamet Martodirdjo as a whole with a value of 7.88. Inventory Logistic Management system is in the good category for the overall variable. 


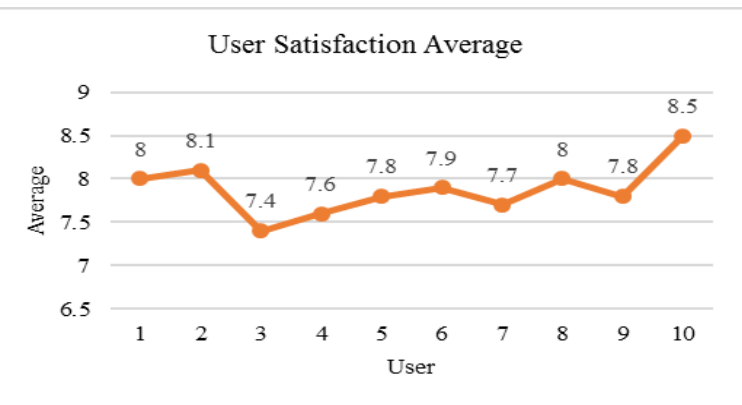

Fig. 7. User Satisfaction Average
Figure 7 is a graph of the average score of user satisfaction. this image makes it easy to read data to draw conclusions. From the results of the questionnaire assessment, it can be concluded that the assessment between users is not much different. this shows the level of objectivity in the assessment process.

At the evaluation stage, data and information come from system testing records. These records are used to improve the overall system. In improving the overall system, the problem does not only come from the previous phase, but can occur in user requirement, analysis, design and implementation phases.

TABLE I. TABLE OF QUETIONNAIRE RESULTS

\begin{tabular}{|c|c|c|c|c|c|c|c|c|c|c|}
\hline \multirow{2}{*}{ No. } & \multicolumn{10}{|c|}{ Value } \\
\cline { 2 - 12 } & $\mathbf{1}$ & $\mathbf{2}$ & $\mathbf{3}$ & $\mathbf{4}$ & $\mathbf{5}$ & $\mathbf{6}$ & $\mathbf{7}$ & $\mathbf{8}$ & $\mathbf{9}$ & $\mathbf{1 0}$ \\
\hline 1 & 8 & 9 & 7 & 8 & 8 & 7 & 7 & 7 & 7 & 8 \\
\hline 2 & 8 & 7 & 7 & 8 & 8 & 8 & 8 & 7 & 8 & 9 \\
\hline 3 & 7 & 8 & 8 & 8 & 8 & 9 & 7 & 8 & 7 & 8 \\
\hline 4 & 7 & 8 & 7 & 7 & 8 & 8 & 8 & 6 & 7 & 9 \\
\hline 5 & 9 & 9 & 8 & 7 & 7 & 8 & 8 & 8 & 8 & 8 \\
\hline 6 & 8 & 7 & 7 & 8 & 8 & 7 & 7 & 9 & 8 & 9 \\
\hline 7 & 7 & 8 & 7 & 8 & 8 & 8 & 8 & 9 & 8 & 8 \\
\hline 8 & 9 & 8 & 8 & 7 & 8 & 7 & 8 & 9 & 8 & 9 \\
\hline 9 & 9 & 9 & 8 & 7 & 7 & 9 & 8 & 8 & 9 & 8 \\
\hline 10 & 8 & 8 & 7 & 8 & 8 & 8 & 8 & 9 & 8 & 9 \\
\hline Average & 8 & 8,1 & 7,4 & 7,6 & 7,8 & 7,9 & 7,7 & 8 & 7,8 & 8,5 \\
\hline
\end{tabular}

\section{CONCLUSION AND FURTHER RESEARCH}

Based on the results of research, the design of the Logistics Inventory Management System in the RSUD. dr. H. Slamet Martodirdjo can be taken several conclusions that the design of a logistics management system with the application of the MVC Codeigniter concept has been implemented well. In the process of implementing software searches for errors that occur and the development process is quite easy because there is a separation of program code into three groups. These groups are models, views and controllers. By using the concept of developing software MVC, makes the processing of a very complex system processing into simple processing. From the research conducted by the authors contributed to the level of effectiveness of the use of MVC in the implementation, development and maintenance of software. From the results of questionnaires that have been given to the logistics management system users, the overall system is good.

\section{ACKNOWLEDGMENT}

This research was supported by the logistics department of the RSUD. dr. H. Slamet Martodirdjo. We give thanks to the entire academic community in the field of informatics engineering who have helped in this research process.
Informatics engineering laboratories that assist in providing equipment support and connections to international journals as well as improving the software development methods that have been carried out. The knowledge that has been given will improve the research that has been done. However, this research needs to be improved for more perfect results. So that further research can be done using different data and different methods.

[1] J. Li, F. Meng, X. Wen, The Design and Realization of Library MIS Based on MVC, Proceedings of 2nd International Conference on Computer and Information Application (ICCIA 2012) Atlantis Press, Peris, Frence, 2012.

[2] A. Hidayat, B. Surarso, Application Of Architecture Model View Controller In Design And Adaptive Online Quiz System, SENAST IKA 2012.

[3] K. Muludi, Implementation Of Framework Model-View-Controller In Lampung University Academic Information System Seminar Nasional Sains \& Teknologi VI, Lembaga Penelitian dan Pengabdian Universitas Lampung, 2015.

[4] A. Hidayat, Application of Model View Controller (MVC) Architecture in Designing Extensions A Content Management. Jurnal Teknologi Informasi dan Komputasi Vol. 3 No. 1, 2012.

[5] D. Prabowo, E-Commerce Website Using Model View Controller (MVC) With Codeigniter Framework Case Study: Miniature Shop Jurnal DASI Vol. 16 No.1. 2015. 
[6] D. Rosmala, M. Ichwan, M.I. Gandalisha, Application Comparison of Codeigniter MVC Framework, and Cakephp on Web Based Applications (Studikasus: Guardianship Information System at the Department of Informatics National Institute of Technology). Jurnal Informatika No. 2 Vol 2, 2011.

[7] S. Balaji, M.S. Murugaiyan, Waterfall vs V-Model Vs Agile: A Comparative Study On Sdlc. International Journal of Information Technology and Bussiness Management Vol.2 No.1.2012.

[8] B.A. Adenowo, A.A.A. Adenowo, Soft ware Engineering Methodologies: A Review of the Waterfall Model and Object-Oriented Approach. International Journal of Scient ific \& Engineering Research, Vol. 4, Issue 7. 2013.

[9] Y. Bassil, A. Senile, Simulator Model for The Waterfall Software Development Life Cycle. International Journal of Engineering and Technology (iJET) Vol. 2, No. 5 . 2012.

[10] A. Alshamrani, A. Bahattab, A Comparison Between Three SDLC Models Waterfall Model, Spiral Model, and Incremental/Iterative Model. IJCSI-International Journal of Computer Science Issues, Vol. 12 issue 1 No. 1. 2015.

[11] D.P. Pop, and A. Altar, Designing an MVC Model for Rapid Web Application Development Elsevier Ltd. Procedia Engineering 69(2014) 1172-1179. 2014. 